\title{
Automation Technology \& its Economic Impact on Indian Economy (A case Study on Module base)
}

\author{
${ }^{1}$ Nand kishor Soni, ${ }^{2}$ Ajay Parashar \\ Department of Economics Barkat Ullah Universaity Bhopal Madhya Pradesh India, Govt. PG College Pipariya
} $(M P)$

\begin{abstract}
Automatic technology is auto manufacturing operations. Its economic impact on Indian Economy explains by Economic Methodology. There is a growing consensus among academicians, business leaders and government officers problem solve by new automation technology into manufacturing operations. Although the source of major innovations is being automation technology in world but Indian firms have been too slow in adopting these technologies. One of the major Factors underlying this problem is the lack of an economic analysis technique specifically aimed at estimating the benefits of automation technology. This paper offers an economic analysis technique based upon the premise of increased probability of capturing the market segments through economies of scope. The paper first demonstrates the inadequacy of current economic analysis techniques to assess the benefits of automation technology, and then proposes a new methodology which can be integrated to an expert system to assess the economic impact of various types of automation technology.
\end{abstract}

Key words: TEPM, CEPIM, CPEM, PBEM, DCF Modules, Current economic technique analysis.

\section{Introduction}

There is abundant evidence that productivity grows more rapidly In countries where Investment In new plant and equipment Is highest. In fact, there Is a growing consensus among academicians, business leaders and government officials that the American competitive problem rests Centrally on the slowing rate of Investment to integrate new automation technology Into manufacturing operations (Kutay, 1989; Hayes et.al., 1988; Cohen and Zysman, 1987). Although the source of major Innovations In automation technology is various universities and research centers, the Indian firms have been too slow In adopting these technologies. One of the major factors underlying this problem is the lack of an economic analysis technique specifically aimed at estimating the benefits of automation technology. This paper attempts to fill this gap by offering an economic analysis technique based upon the premise of increased probability of capturing the market segments through economies of scope. In the subsequent sections of the paper, it is first demonstrated that the conventional economic theory upon which the current economic impact methods are based cannot assess the economic benefits of automation technology. In the mass production system, capital Investments in new technology could usually be justified by their potential to replace human labor by machines to Improve productivity. In the new system of flexible production, however, the economic foundations of the benefits derived from automation technology are fundamentally different from the benefits obtained from capital Investments on new technology in the mass production system. The use of conventional methods of economic performance, such as productivity Improvements, would merely be a measurement of the potential benefits that could be obtained from automation technology. In section two, a new conceptual framework is developed to evaluate the economic Impact of automation technology. The new conceptual framework suggests that the economic foundation of the benefits of automation technology is the economies of scope based upon the premise of shorter lead times, increased flexibility In production, and improved product quality. In section three, it is demonstrated that the economic Impact of automation technology, considered 'intangible" and therefore left un quant fled in conventional economics, can be evaluated through potential gains In Inventory costs, sales revenue, and lower operating and labor costs due to improvements In lead times, flexibility In production, and product quality, it is suggested that the entire analysis can be Integrated Into a standard economic justification technique such as Discounted Cash Flow analysis, to make It understandable to company managers, accountants, and economists. An expert system can then be developed to aid the users of automation technology to Identity the benefits they may obtain from Its Implementation. Once the model of economic Impact analysis of automation technology developed In this paper $\mathrm{s}$ tested, the ultimate goal is to develop an expert system to achieve the following: 1. Prior to the Integration of a new technology, the expert system will enable a company to Identify the areas In the manufacturing process In which the use of automation technology would be economically viable. Industrial revolution when mass production and mass consumption prevailed in the world economy. In the system of mass production, the major production strategy to expand profits was to Increase the size of the total target market. The major dilemma a firm faced to meet competition was therefore to lower unit costs to expand the size of the market for its product. The unit costs were lowered through economies of scale (i.e., producing an Increasing quantity of the some 
product) and by lowering labor and raw material costs through capital Investments. The economic performance of a firm, an Industry, or the larger macro economy was therefore evaluated productivity which measured the Increase In output relative to a unit increase in capital, labor and raw materials.

\section{Literature Review}

There is a considerable dearth of literature on this topic, with one notable exception, which is discussed starting in the following paragraph. The other references to the topic are found, in the main, in media reports, campus publications, and Web publications. A sample of these references is also referenced below. The research In this area, however, tends to emphasize either direct labor displacement effects without considering the changes In the nature of work (for example Ayres and Miller, 1983), or tends to be advocacy type of efforts which assert the existence of certain benefits from automation technology without explaining the precise source of these benefits (Hayes et.al., 1988; Cohen and Zysman, 1987; Jellnek and Goldhar (1984).The first economic or societal impact studies of automation technology overwhelmingly emphasized labor displacement Issues which unfortunately encouraged the formation of a hostile attitude toward automation technology particularity on the labor side. While It is $t m$ that automation technology replaces human labor directly Involved In the production of goods on the factory floor, it creates more jobs In processes Involved In the production of goods. Automation technology transforms the nature of work from directly contributing to the production of finished goods to contributing to production indirectly by generating information to reduce uncertainty in decisions related to the production, exchange, circulation, distribution and consumption of goods (Cohen and Zysman. 1987). Consequently More Jobs are created in setting up the production systems, in designing the products, in R\&D efforts, and In finance, marketing, and distribution stages of production. Direct human labor In production has nevertheless been reduced for repetitive and hazardous tasks where displacement is more advantageous for labor In the long term. One of the key arguments of this paper is that the lack of an economic analysis technique specifically aimed at assessing the benefits of automation technology is the major cause of the confusion observed In the prior studies of automation. In the next section we direct the attention to the Inadequacy of conventional economic theory to assess the benefits of automation technology.

\section{Analysis of economic Impact of Automation technology on Indian Economy}

The economic Impact of analysis aimed at integrating new technology or equipment into the Manufacturing operations of Indian firms. In the firms of a capital Investment procedure which typically allocates current resources in the prospect of future returns by following module:-

\section{Total Expected Profit Method (TEPM)}

The economic justification of replacing a conventional Economic method with an automated method is becoming more complex as technology advances. Most of these automated technologies are expensive when considering only initial capital investments. Traditionally, automated technologies have been justified by applying a general expected savings analysis this analysis may be an appropriate method for the mass production system of the manufacturing industry. TEP can be determined by the following equation;

$$
\mathrm{TEP}=\mathrm{Y}-\mathrm{Bt}(1+\mathrm{i})-\mathrm{t}-\mathrm{Y}-\mathrm{Ct}(1+\mathrm{i})-\mathrm{t}+\mathrm{LC}
$$

$$
\mathbf{t}=\mathbf{0} \mathbf{l} \mathbf{t}=\mathbf{0}
$$

Total project bids is the summation of the yearly project bids, and Bt, over the user defined period, $\mathrm{n}$, which has to be set equal to several economic life cycles of the evaluated technology. Total costs related to the automation technology can be composed of initial investment cost to adapt the technology, I.C., yearly operating costs, $\mathrm{Ct}$, which includes maintenance costs and labor costs required to operate the technology. Yearly costs and yearly project bids can be evaluated at the end of each year through digital simulation, and then adjusted to the present value with the user-defined minimum attractive rate of return, i. Since the total expected profit of each method is simulated under the same condition, the method with the greater total expected profit should be selected as the economical method.

\section{Cost and Economic Performance Information Module (CEPIM)}

As pointed out in this section. The benefits derived from new automation technology are fundamentally different from the benefits obtained from capital Investments in the mass production system. Using the conventional methods of economic performance information module would only measure the potential benefits that could be obtained from new automation technology. This module is a database file management program whose functions are as follows:

(1) To provide cost and performance information on the automation technology for the simulation process.

(2) To provide project type information to the PBEM. 
(3) To store project bids and project operating costs, which will be provided to the TEPM?

\section{Cost and Economic Performance Evaluation Module (CEPEM)}

This module is a digital simulation program, and its functions are as follows:

(1) To calculate project duration based on performance parameters of the technology for the given project information.

(2) To generate detailed annual project cost data for each project over the user-defined time periods.

(3) To convert contractor's credibility improvement from the qualitative benefit into numerical values by using statistical parameters. CPEM performs simulation over the user-defined period that has to be set at several economic service lives of the automation technology in order to calculate its life cycle cost. CPEM will first schedule all the projects with the starting date and its type over the time period. Information related to each project type will be extracted from the project information file in the CPIM.

\section{Project Bids Estimation Module (PBEM),}

The functions of this module are as follows:

(1) To calculate unit cost per hour for owning and operating construction technology being evaluated.

(2) To calculate material cost and labor cost from the information on the given project type.

(3) To estimate the project bids with the calculated separate cost items and the predefined overhead percentage and profit margin. Information on the performance of the construction technology being evaluated and information on the project type generated in the simulation are extracted from the database files in the CPIM, respectively. Project bids estimated in this module will be accumulated until the end of each year. This amount represents yearly income of the contractor and will be stored in the project bid database file in the CPIM if the bid is successful.

\section{Discounted Cash Flow Module (DCF)}

Discounted Cash Flow Module analysis is aimed at measuring the economic returns on Investment of new technology over time. DCF analysis is based on the concept of "time value of money' approach. The basic Idea underlying this approach Is to translate the returns that can be obtained from a certain Investment over a certain period of time Into an amount equivalent to a value today. All cash Inflows (benefits) and outflows (costs) associated with an Investment are discounted to a certain value today so that the magnitude of Investment is not larger than the present value of future savings. The discounting function serves to make cash flows received in the future equivalent to cash flows received at the present. There are other capital Investment evaluation methods such as the payback, payback reciprocal, and accounting rate of return which are simpler to use than the DCF method but ignore the time value of cash flows. These methods became economical at higher outputs sourcing in scale of economies.

\section{Conclusion}

This stage includes a detailed of all broad scale benefits and costs Identified In the first stage within standard accounting categories and their quantification using the existing accounting records of a firm or manufacturing plant. Identification of costs and benefits within the standard accounting categories enables their precise quantification since data on those Items should normally be available in the accounting records like as Reduction in Inventory costs. The new automation technology, on the other hand, offers the possibility of reducing stock levels in work-In-process (WIP), finished goods and raw material Inventory due to greater predictability of the production process, faster throughout times and due to the reduction of scrap and rework. Calculating the financial savings resulting from a given Inventory reduction is more complex than normally assumed. The only benefit Item that has been Included In prior studies has been the direct Reduction In labor cost Automation technology reduces labor costs in the design, production and maintenance stages as well as in the supervision and Inspection of the manufactured components or products. Although labor costs currently constitute 8 to $12 \%$ of total production costs, the magnitude in savings should still be Included In the economic Impact analysis. Automation technology offers the potential to reduce labor costs in the design, production and maintenance stages as well as in supervision and Inspection of the components. Capital Investments in new technology could therefore be justified by their potential to replace human labor with machines to Increase productivity. Finally, productivity Improvements through the increased use of machinery was only possible through further standardization of products which led to a substantial decline in unit production costs. Given the emphasis of lowering the unit costs of standardized products to expand the total target market size, productivity was perfectly relevant to measure economic performance in the system of mass production. Once the world markets began to saturate during the 1960s and the 1970s, it became increasingly clear that mass production of standardized products was no longer profitable since the size of the total target market could not be expanded. At the same time, with an Increase in International competition, the number of manufacturers attacking a market 
multiplied, resulting in a large number of differentiated product versions on the market. The emphasis to gain the markets shifted from economies of scale to economies of scope. That $I S$, manufacturers produced a variety of products to satisfy a far greater range of market needs by increasing the capacity to manufacture goods cheaply in small batches. Even If the size of the total target market could not be increased (or even if the size of the pie could not be expanded). Economies of scope ascertained that the probability of actually capturing the targeted total market could be increased through product different relation. New trends toward Internationalization of the world economy also Increased competition which, in turn propelled the need to shorten the period of time necessary to introduce a variety of products to the market In small batches. As one can see, these trends In flexible production were In contrast to the way firms competed In the system of mass production by producing large quantities of similar products. The new automation technology consequently became crucial in production since it Improved product lead time, product quality, and the capability to Increase by automatic production system. When the economic system started to change, one expected to a see a change in the performance measures of the economic system. While the measure of economic performance through labor, raw material, and multiple factors productivity were perfectly relevant in the system of mass production, these techniques were Inadequate to measure economic performance in flexible production. The paper point is that, the economic foundations of the benefits derived from new automation technology are fundamentally different from the benefits obtained from capital Investments In the mass production system. The use of conventional methods of economic performance, such as productivity, would merely measure the potential benefits that could be obtained from automation technology. The main benefits of automation technology, such as reduced lead times, faster response to market shifts, and increased flexibility in product differentiation, do not enter Into the calculus of the conventional measures of economic performance. It is no wonder that productivity studies of Information technology conclude that user firms have not experienced productivity gains from automation technology. The main benefits of automation technology such as reduced lead times, faster response to market shifts, and Increased flexibility in product differentiation as well as Its enhanced capabilities to produce complex products of higher quality and reliability levels, do not enter the calculations of the conventional measures of economic performance. In this section, a new' conceptual framework which can readily Integrate the benefits of automation technology in the calculations of the Improvements In economic performance, is developed.

\section{Acknowledgement}

I would like to gratefully and sincerely thank Dr. M. K. Singhai, his guidance, understanding, patience, and most importantly, his friendship during my preparing research paper and V. Sharma, His mentorship was paramount in providing a well rounded experience consistent my long-term career goals. I would also like to thank Dr. P. K. Jain, his assistance and guidance in getting my career started on the right foot and providing me with the foundation for becoming a synthetic data. Although his decision to promote my efficiency. Finally, and most importantly, I would like to thank my friends Arvind Mishra. He support, encouragement, quiet patience and unwavering love were undeniably the bedrock upon which the past ten years of my life have been built. Her tolerance of my occasional vulgar moods is a testament in itself of her unyielding devotion and love. I thank my parents, Shri Maheshwari Deen Soni and Smt. Tulsa for their faith in me and allowing me to be as ambitious as I wanted. It was under their watchful eye that I gained so much drive and an ability to tackle challenges head on.

\section{References}

Anil Kapoor "Business Week (2013) *Special Report: Product Quality. April 21.

[1]. Cohen, S. and Zysman, J. (1987) 'Manufacturing Matters, * Basic Books. New York.

[2]. Dean, E. and K. Kunze (1988) *Recent changes in the growth of U.S. multifactor productivity'

[3]. Monthly Labor Review. May 2013.

[4]. D.J. Fisher and J.T. O'Connor. "Constructability for Piping Automation: Field Operations" ASCE, Vol. 117, No. 3, September 1991, pp. $468-485$

[5]. $\quad$ Hayes, R.H. Wheelwright, S.C. Clark, K. (1988) 'Dynamic Manufacturing,' the Free Press, New

[6]. York.

[7]. J.J. Rho, D.J. Fisher, and M.W. O'Neill. A Systems Approach to the Integration of Automation Technology in Drilled Shaft Construction Presented to 72nd Transportation Research Board Meeting. Washington D.C., January 1993.

[8]. J.L. Riggs and T.M. West. Engineering Economics, Third Edition. McGraw- Hill, New York, 1986.

[9]. Kaplan, R.S. (1989) 'Cost accounting distorts product costs. Harvard Business Review, January-

[10]. February 2009

[11]. Kaplan, R.S. (1986) 'Must CIM be justified by faith alone?' Harvard Business Review, March-April.

[12]. Kutay, A. (1988a) 'The changing organization of production in flexible manufacturing systems', Paper presented at the American Planning Association Meetings, October 2013

[13]. Kutay, A. (1988b) *Impacts of telecommunications Technology on Organizational Structures

[14]. and Employment, Paper presented at the European Meetings of the RSA, Lake Garda, Italy, July, and August 2013

[15]. Kutay, A. (1988c) 'Technological change and spatial transformation In an Information economy,' Environment and Planning A, v.20. 
[16]. Kutay, A. (1989) 'The Structural Transformation of the U.S. Economy: Implications for Labor and Technology policy'. Paper presented at the ASME-COSSA Conference. Also In, Proceedings American Society of Mechanical Engineers, Symposium on Worker in Transition: Technological Change', April 2013

[17]. Loveman, G.W. (1988) 'An assessment of the productivity Impact of Information technologies'.

[18]. Sloan School of Management, MIT. 